\title{
Phototrophic nutrition and symbiont diversity of two Caribbean sponge-cyanobacteria symbioses
}

\author{
Patrick M. Erwin, Robert W. Thacker* \\ University of Alabama at Birmingham, 109 Campbell Hall, 1300 University Boulevard, Birmingham, \\ Alabama 35294-1170, USA
}

\begin{abstract}
Coral reef sponges frequently harbor symbiotic cyanobacteria that can potentially benefit their hosts by providing supplemental nutrition. Although nutritional mutualisms have been documented for Indo-Pacific sponges, previous investigations suggest that Caribbean sponges obtain no nutritional benefits from their symbionts. We conducted field-based shading experiments to determine the effects of reduced irradiance on symbiont abundance and host growth in the Caribbean coral reef sponges Aplysina fulva and Neopetrosia subtriangularis, both of which host the unicellular cyanobacterium Synechococcus spongiarum. For both host species, 6 wk of shading significantly reduced chlorophyll a concentrations to less than half of those in control sponges. Shaded A. fulva individuals exhibited less than half the growth of control sponges. For N. subtriangularis, no significant differences in growth rates were observed between shaded and control sponges. Measurements of gross photosynthesis to respiration (P:R) ratios predicted that both host sponges were heterotrophic at low irradiances $\left(<250 \mu \mathrm{mol} \mathrm{m} \mathrm{m}^{-2} \mathrm{~s}^{-1}\right)$ and phototrophic at high irradiances $\left(>500 \mu \mathrm{mol} \mathrm{m} \mathrm{m}^{-2} \mathrm{~s}^{-1}\right)$, with measurements obtained at high irradiances likely to be more indicative of natural conditions. Phylogenetic analyses of cyanobacterial internal transcribed spacer (ITS) ribosomal RNA gene sequences revealed 3 genetically distinct clades of $S$. spongiarum (designated A, B and C). Clade A symbionts were isolated exclusively from A. fulva, Clade B symbionts from both host sponge species and Clade C symbionts exclusively from $N$. subtriangularis. These findings demonstrate that Caribbean sponges associate with diverse clades of cyanobacterial symbionts that may confer variable nutritional benefits; in some cases, these symbionts appear to substantially enhance host growth rates.
\end{abstract}

KEY WORDS: Symbiosis $\cdot$ Sponge $\cdot$ Cyanobacteria $\cdot$ Primary productivity $\cdot$ Respiration

\section{INTRODUCTION}

Coral reefs are among Earth's most productive ecosystems and support a remarkable diversity and abundance of marine life; however, these habitats are generally characterized by low nutrient availability, intense competition for space and light, and heavy grazing pressures (Birkeland 1997). To cope with these environmental demands, many sessile invertebrates form symbioses with photosynthetic organisms, in which autotrophic symbionts contribute to the metabolic and energetic needs of the host (Muscatine \& Porter 1977), thereby enhancing host growth rates and competitive ability. These symbioses are exempli- fied by mutualistic coral-dinoflagellate associations, whose evolution yielded the formation of coral reef habitats (Stanley 2006), and span a wide range of invertebrate host taxa, including tridacnid clams, anemones, ascidians and sponges (Rützler 1990).

Coral reef sponges most commonly harbor cyanobacteria as photosynthetic symbionts (Rützler 1990), but also form associations with filamentous algae (Carballo \& Ávila 2004) and dinoflagellates (Schönberg \& Loh 2005). Although cyanobacterial symbionts can comprise 25 to $50 \%$ of a sponge's cellular volume (Rützler 1990), relatively little is known about the metabolic exchanges and ecological interactions between sponges and their microbial symbionts (Tay- 
lor et al. 2007a). Symbiotic cyanobacteria may benefit host sponges through supplemental nutrition (Arillo et al. 1993), nitrogen fixation (Wilkinson \& Fay 1979), production of secondary metabolites (Flatt et al. 2005) and UV protection (Regoli et al. 2000), suggesting key roles for these symbionts in the evolutionary history and ecological success of coral reef sponges.

Although sponge-associated cyanobacteria span at least 6 genera (Steindler et al. 2005, Taylor et al. 2007a), a sponge-specific lineage of Synechococcus represents the most prevalent symbiont group (Erwin \& Thacker 2007). The initial description of this species, 'Candidatus Synechococcus spongiarum', was based on the distinct morphology and unique 16S ribosomal RNA (rRNA) gene sequences of cyanobacteria associated with the host sponge Chondrilla nucula (Usher et al. 2004). Similar ribotypes have been characterized from at least 20 sponge species, which represent 12 families and 8 sponge orders, and inhabit tropical and temperate reefs around the world (Steindler et al. 2005, Thacker 2005). Phylogenetic analyses of $S$. spongiarum $16 \mathrm{~S}$ rRNA sequences from these host species revealed a genetically distinct symbiont clade clearly differentiated from freeliving cyanobacteria, but with little consistent genetic differentiation within this clade based on host taxonomy or geographic location (Steindler et al. 2005, Thacker 2005). Similarly, comparative morphological analyses of $S$. spongiarum using electron microscopy reported indistinguishable symbiont populations inhabiting disparate hosts from distant geographic regions (Usher et al. 2006). Taken together, these studies suggest that $S$. spongiarum may represent a generalist symbiont capable of horizontal transmission among hosts and widespread dispersal across the oceans.

The contribution of cyanobacterial symbionts to host sponge nutrition has been estimated by measuring photosynthetic rates and gross primary productivity to respiration (P:R) ratios of intact holobionts (Wilkinson 1987). Symbioses with a P:R ratio exceeding 1.5 were defined as phototrophic sponges, receiving supplemental nutrition from the products of symbiont photosynthesis (Wilkinson 1987). Although phototrophic species were common on Pacific coral reefs, previous investigations suggested that they were absent in the Caribbean (Wilkinson 1987). Since photosynthetic rates and metabolic exchanges are not necessarily correlated, additional measurements are often required to infer the nutritional contribution of symbionts to their hosts (Muscatine et al. 1981). Field-based shading experiments provide direct evidence for the ultimate role of photosymbionts by testing the effects of reduced sunlight exposure on symbiont load and host sponge growth and survival. Such experiments have been conducted for Indo-Pacific (e.g. Thacker 2005) and Mediterranean sponges (e.g. Arillo et al. 1993).
We assessed the nutritional contribution of symbiotic cyanobacteria to Caribbean coral reef sponges by experimentally shading 2 common sponge species, Aplysina fulva and Neopetrosia subtriangularis, and monitoring chlorophyll a (chl a) concentrations and holobiont growth over a 6 wk period. These empirical data were compared to predictions of symbiontderived nutritional benefits based on post-experiment measurements of $\mathrm{P}: \mathrm{R}$ ratios. Symbiont identities were confirmed and fine-scale variability between host sponge populations was assessed using cyanobacterial 16S rRNA and 16S-23S rRNA internal transcribed spacer (ITS) gene sequences.

\section{MATERIALS AND METHODS}

Sponge collection and experimental design. The sponges Aplysina fulva and Neopetrosia subtriangularis were collected from STRI Point, Bocas del Toro, Panama $\left(9^{\circ} 21^{\prime} 7^{\prime \prime} \mathrm{N}, 82^{\circ} 15^{\prime} 32^{\prime \prime} \mathrm{W}\right)$ at depths of 2 to $3 \mathrm{~m}$. A. fulva and $N$. subtriangularis are abundant members of the reef sponge community in these shallow waters, representing the 2nd and 5th most abundant sponge species, respectively (Erwin \& Thacker 2007). Both species exhibit a rope-like morphology with occasional bifurcating branches. A. fulva individuals inhabiting the reefs of Bocas del Toro range in color from yellow to reddish brown, with a compressible consistency. $N$. subtriangularis individuals range in color from yellowish-brown to dark brown, with a brittle, hard consistency. A total of 10 individuals per species were collected; each individual was divided into 2 small pieces (approximately $3 \mathrm{~cm}$ long) and 4 large pieces (approximately $10 \mathrm{~cm}$ long). One small piece was preserved in RNAlater (Ambion) for genetic characterization of symbionts, while the other was used for initial chl a quantification (see 'Chl a quantification'). From each source individual, 2 large pieces were randomly assigned to the control treatment and 2 to the shaded treatment; each pair was housed in a separate canopy, for a total of 10 control and 10 treatment canopies.

Canopies consisted of a $15 \mathrm{~cm} \times 15 \mathrm{~cm}$ square plastic grating base attached by plastic cable ties to a $30 \mathrm{~cm} \times$ $30 \mathrm{~cm} \times 3 \mathrm{~mm}$ acrylic (Lucite-ES, INEOS Acrylics) roof with 4 PVC pipes of length $10 \mathrm{~cm}$ located in the corners. Acrylic canopies were either transparent to visible light for control treatments or opaque for shaded treatments, which reduced the light availability to approximately $7 \%$ of ambient irradiance. Each sponge was measured for initial wet mass (after a standardized blotting with paper towels) and displacement volume, then attached to respective control or shaded canopies and deployed in the field for $6 \mathrm{wk}$. 
One sponge per canopy was sampled each week to monitor chl a concentrations; the other sponge was left undisturbed to ensure accurate mass and volume measurements at the end of the experiment. Following final measurements of mass and volume, sponges were divided into 3 pieces: one preserved in $95 \%$ ethanol as a morphological voucher, one preserved in RNAlater for genetic characterization of symbionts, and one used for final chl a quantification. Growth rates were calculated as percentage change [(final - initial)/initial $\times$ 100]; randomized block ANOVAs were used to detect significant $(p<0.05)$ differences between the growth rates of paired control and shaded replicates obtained from the same source individual using SYSTAT v. 11. While no sponges suffered complete mortality, sponges were removed from the final analyses if (1) they exhibited negative growth due to predation (5 out of 40 pieces), (2) the treatment cages detached from the substrate (1 out of 40 pieces) or (3) samples were overgrown by algae (1 out of 40 pieces). Additionally, paired replicates of sponges removed from the analyses were also removed (5 out of 40 pieces) to maintain balanced statistical analyses.

Chl a quantification. For each sponge piece, $0.25 \mathrm{~g}$ of ectosome was extracted in $10 \mathrm{ml}$ of $90 \%$ acetone. Samples were wrapped in foil to prevent photodegradation of chlorophyll and held overnight at $4^{\circ} \mathrm{C}$. Subsequently, $1.5 \mathrm{ml}$ of extract was transferred to a microcentrifuge tube and centrifuged to pellet-suspended particles; $1.0 \mathrm{ml}$ of supernatant was then transferred to a spectrophotometric cuvette and absorbances were quantified at 750,664, 647 and $630 \mathrm{~nm}$. Chl a concentrations were estimated from these absorbances using the equations of Parsons et al. (1984) and standardized per sponge mass extracted. Control and shaded treatments were compared over 6 wk by repeated measures ANOVA using SYSTAT v. 11.

Photosynthesis and respiration measurements. After 6 wk of shading, 4 pairs of control and shaded sponges from each of the 2 species were attached to plastic grating using plastic cable ties and held in an outdoor, flow-through, filtered-seawater aquarium for $7 \mathrm{~d}$. Photosynthesis and respiration rates were measured in a closed-chamber incubation apparatus that consisted of 4 glass cylinders set in 2 rectangular water baths. Cylinders were filled with filtered seawater, and initial dissolved oxygen (DO) concentrations and temperatures were measured using a YSI-85 DO meter (YSI Environmental). To measure net photosynthesis rates, sponges were added to the cylinders and exposed to ambient sunlight for $1 \mathrm{~h}$. To measure respiration rates, sponges were incubated at night for $2 \mathrm{~h}$. During daylight incubations, light availability was manipulated using window screening and measured at least every 15 min using a LI-1400 Datalogger (LiCor).
After incubation, sponges were removed from the cylinders and final DO concentrations and temperatures were measured. Gross photosynthesis was calculated as net photosynthesis plus respiration.

Isolation, cloning and sequencing of symbiont DNA. Although intragenomic variation can complicate the analysis of ITS sequences for some cyanobacteria, Synechococcus spp. and other unicellular cyanobacteria possess only 2 identical copies of the rRNA operon (Stewart \& Cavanaugh 2007). Rocap et al. (2002) suggested that the $16 \mathrm{~S}-23 \mathrm{~S}$ rRNA ITS region could be a useful marker to distinguish among strains of Synechococcus. Genomic DNA was extracted from 5 Aplysina fulva and 5 Neopetrosia subtriangularis specimens preserved in RNAlater using the Wizard Genomic DNA Purification Kit (Promega); extracts were cleaned using the Wizard DNA Clean-Up System (Promega). The cyanobacteria-specific oligonucleotide primers CYA781F (Nübel et al. 1997) and CYA23S1R (Primer 340, Iteman et al. 2000) amplified the 3 ' end of the $16 \mathrm{~S}$ rRNA gene (737 bp) and the complete 16S-23S ITS region (492-496 bp). Total PCR reaction volume was $50 \mu \mathrm{l}$, including $25 \mathrm{pmol}$ of each primer, $10 \mathrm{nmol}$ of each dNTP, $1 \times$ MasterTaq PCR Buffer (Eppendorf) and $1 \times$ TaqMaster additive (Eppendorf). Thermocycler reaction conditions included an initial denaturing time of $5 \mathrm{~min}$ at $85^{\circ} \mathrm{C}$, followed by the addition of 1.0 unit MasterTaq DNA polymerase (Eppendorf), then 30 cycles of $1.5 \mathrm{~min}$ at $94^{\circ} \mathrm{C}, 2 \mathrm{~min}$ at $50^{\circ} \mathrm{C}$ and $3 \mathrm{~min}$ at $72^{\circ} \mathrm{C}$, and a final extension time of $10 \mathrm{~min}$ at $72^{\circ} \mathrm{C}$. PCR reaction products were gel-purified and cleaned using the Wizard PCR Preps DNA Purification System (Promega), then ligated into plasmids using the pGEM-T Easy Vector System (Promega); plasmids were harvested using the QIAprep Spin Miniprep Kit (QIAGEN). At least 3 separate clones were sequenced from each sponge individual. If dissimilar clones were recovered, 4 or 5 additional clones were sequenced. Forward and reverse sequencing reactions were performed for each clone at the University of Alabama at Birmingham (UAB) Center for AIDS Research (CFAR) DNA Sequencing Core Facility.

Phylogenetic analysis of symbiont DNA sequences. Forward and reverse sequences were compared using Sequencher (Gene Codes) to ensure the accuracy of sequencing results. Consensus sequences were deposited in GenBank under accession numbers EF121775 to EF121812 and were aligned using Clustal X (Thompson et al. 1997). GenBank BLAST searches identified the most closely related sequences to the sponge-associated clones. Sequences from GenBank used as outgroup comparisons included the top 3 BLAST matches (AY033310, DQ009327 and DQ900359) and 4 cultured cyanobacterial sequences from Synechococcus Marine Cluster 5.1 (AF397728, 
AF397713, AF397721, and AF397727; Rocap et al. 2002). ITS region sequences were annotated by comparison to sequences obtained by Iteman et al. (2000). All ITS sequences contained 2 transfer RNA (tRNA) coding regions (tRNA-Ile and tRNA-Ala). Spongeassociated clones exhibited less than $1 \%$ sequence divergence in the $16 \mathrm{~S}$ region but approximately $7 \%$ sequence divergence in the ITS region. A partition homogeneity test was conducted using PAUP* 4.0 (Swofford 1998) to assess congruence between phylogenies constructed using all sequence data (16S and ITS) and only the ITS region. Since this test yielded identical tree topologies $(\mathrm{p}=1.00)$, subsequent phylogenetic analyses used only the ITS region.

Neighbor-joining (NJ) phylogenetic analysis of aligned DNA sequences was performed using MEGA 3.1 (Kumar et al. 2004), with the Kimura 2-Parameter model of nucleotide substitution. Data were resampled using 1000 bootstrap replicates. Maximum parsimony (MP) and maximum likelihood (ML) phylogenetic analyses were performed using PAUP* 4.0 (Swofford 1998). For MP analysis, a heuristic search was performed with 100 random additions, a maximum of 10 trees retained at each step, and an overall maximum of 1000 trees. The stepwise-addition and tree bisection reconnection algorithms were implemented with default settings and the data were resampled using 100 bootstrap replicates. For ML analysis, Modeltest 3.06 (Posada \& Crandall 1998) was used to select the best model of DNA substitution: the HasegawaKishino-Yano model with a gamma distribution of variable substitution rates among sites $(\mathrm{HKY}+\mathrm{G})$. ML analysis was performed using a heuristic search; data were resampled using 100 bootstrap replicates. For Bayesian analyses, MrBayes 3.1.2 (Ronquist \& Huelsenbeck 2003) was used to calculate the posterior probabilities of branch nodes, implementing the HKY+G likelihood model. The Monte Carlo Markov Chain length was set at 1 million generations with sampling every 100th generation and a burn-in value of 2500 cycles. After 882000 generations, the average $\mathrm{SD}$ of split frequencies reached less than 0.01 .

\section{RESULTS}

Experimental shading reduced symbiont chl a concentrations in both sponge-cyanobacteria symbioses investigated. In Aplysina fulva, chl a concentrations steadily decreased in shaded treatments throughout the experimental period and, following an early stressinduced reduction, controls recovered to initial $\mathrm{chl} a$ concentrations by Week 4 . After 3 wk, chl a concentrations were significantly different between shaded and control sponges and by the end of the experiment, chl a concentrations in shaded treatments were less than half $(45 \%)$ those of control sponges (Fig. 1A, Table 1). In Neopetrosia subtriangularis, shaded treatments displayed similar reductions in chl a concentra-

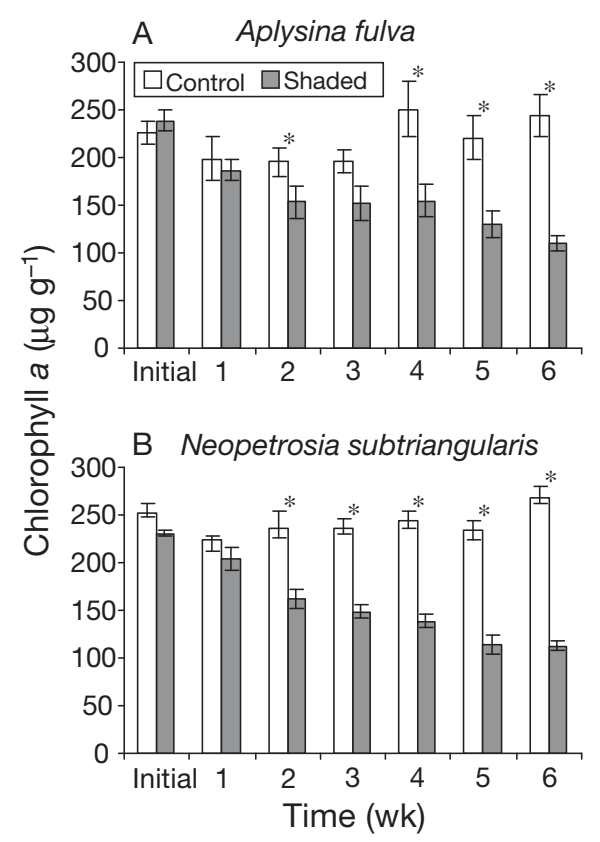

Fig. 1. (A) Aplysina fulva ( $\mathrm{n}=6$ ) and (B) Neopetrosia subtriangularis $(\mathrm{n}=9$ ). Effect of shading on weekly measurements of chl a concentrations $\left(\mu \mathrm{g} \mathrm{g}^{-1}\right.$; mean $\left.\pm 1 \mathrm{SE}\right) * \mathrm{p}<0.05$ for the difference between control and shaded treatments

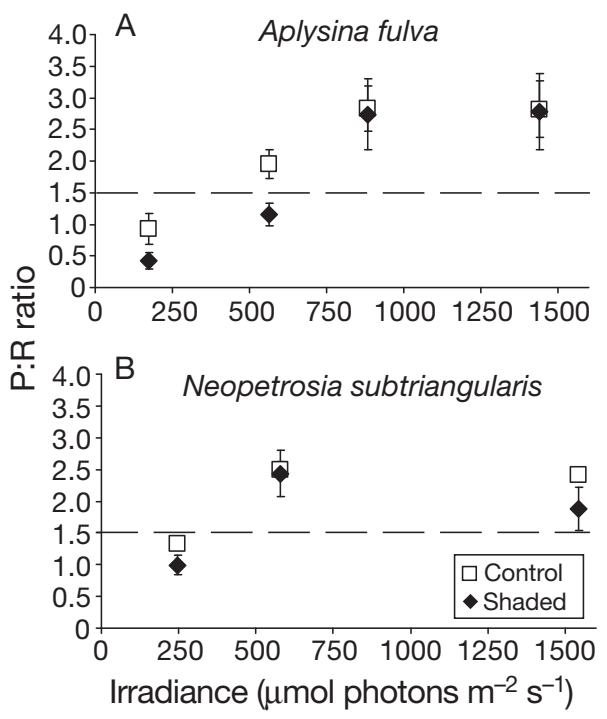

Fig. 2. (A) Aplysina fulva and (B) Neopetrosia subtriangularis. Effect of shading on gross productivity to respiration $(\mathrm{P}: \mathrm{R})$ ratios (mean $\pm 1 \mathrm{SE}_{i} \mathrm{n}=4$ ). Dashed lines represent the threshold P:R ratio used by Wilkinson (1987) to define sponge-cyanobacteria symbioses as heterotrophic $(\mathrm{P}: \mathrm{R}<1.5)$ or phototrophic $(\mathrm{P}: \mathrm{R}>1.5)$ 
Table 1. Aplysina fulva and Neopetrosia subtriangularis. Repeated-measures ANOVA in chl a concentrations over 6 wk of shaded and control conditions

\begin{tabular}{|lrrrrr|}
\hline Source & Sum of squares & df & Mean square & F-ratio & \multicolumn{1}{c|}{$\mathrm{p}$} \\
\hline A. fulva & & & & & \\
Between subjects & & & & & \\
$\quad$ Individual & 59752.601 & 7 & 8536.086 & 20.735 & 0.015 \\
Treatment & 57967.360 & 1 & 57967.360 & 140.807 & 0.001 \\
Error & 1235.042 & 3 & 411.681 & & \\
Within subjects & & & & & \\
Time & 32739.655 & 6 & 5456.609 & 5.501 & 0.002 \\
Time $\times$ Individual & 49393.448 & 42 & 1176.034 & 1.185 & 0.358 \\
Time $\times$ Treatment & 45902.126 & 6 & 7650.354 & 7.712 & $<0.001$ \\
Error & 17856.304 & 18 & 992.017 & & \\
$\mathbf{N}$ subtriangularis & & & & & \\
Between subjects & & & & & \\
Individual & 8894.243 & 8 & 1111.780 & 0.577 & 0.773 \\
Treatment & 217829.899 & 1 & 217829.899 & 113.056 & $<0.001$ \\
Error & 15413.947 & 8 & 1926.743 & & \\
Within subjects & & & & & \\
Time & 51120.341 & 6 & 8520.057 & 14.615 & $<0.001$ \\
Time $\times$ Individual & 46723.969 & 48 & 973.416 & 1.670 & 0.039 \\
Time $\times$ Treatment & 67279.973 & 6 & 11213.329 & 19.234 & $<0.001$ \\
Error & 27983.094 & 48 & 582.981 & & \\
\hline
\end{tabular}

load (chl $a: t=4.771$, $\mathrm{df}=4, \mathrm{p}=0.009$ ) and grew significantly less than controls (volume: $t=5.440, \mathrm{df}=4, \mathrm{p}=$ 0.006; mass: $\mathrm{t}=3.959$, $\mathrm{df}=4, \mathrm{p}=$ 0.017), exhibiting less than half the volume (36\%) and mass gain ( $40 \%$ ) of control sponges over the $6 \mathrm{wk}$ experimental period (Fig. 3A). In contrast, experimental shading of $N$. subtriangularis yielded no significant differences in growth between shaded and control individuals (volume: $t=0.307$, $\mathrm{df}=8, \mathrm{p}=0.767$; weight: $\mathrm{t}=-0.187$, $\mathrm{df}$ $=8, \mathrm{p}=0.856)$, despite a reduced symbiont load in shaded sponges (chl a: $t=$ 7.702, df = 8, p < 0.001; Fig. 3B).

Symbiont 16S rRNA gene sequences formed a monophyletic clade with the sponge-specific cyanobacterium, 'Candidatus Synechococcus spongiarum' (Usher et al. 2004) and related sponge-derived cyanobacterial sequences (Steindler et al. 2005, Thacker 2005) and were clearly differentiated tions throughout the experimental period, while controls recovered to initial chl a concentrations by Week 2. After $2 \mathrm{wk}$, chl a concentrations were significantly different between shaded and control sponges and by the end of the experiment, chl a concentrations in shaded treatments were less than half $(42 \%)$ those of control sponges (Fig. 1B, Table 1).

Photosynthetic output and $\mathrm{P}: \mathrm{R}$ ratios of shaded sponges were also reduced compared to controls at lower irradiances in both host sponge species; however, no significant differences between shaded and control sponges were observed at any irradiance for either host species (Fig. 2, Table 2). P:R ratios were lower in shaded Aplysina fulva sponges compared to controls at lower irradiances $\left(<750 \mu \mathrm{mol} \mathrm{m} \mathrm{m}^{-2} \mathrm{~s}^{-1}\right)$ and lower in shaded Neopetrosia subtriangularis sponges compared to controls at the lowest irradiance $\left(246 \mu \mathrm{mol} \mathrm{m} \mathrm{m}^{-2} \mathrm{~s}^{-1}\right)$. A. fulva and $N$. subtriangularis were classified as heterotrophic sponges $(\mathrm{P}: \mathrm{R}<1.5)$ when measured at lower irradiances $\left(<250 \mu \mathrm{mol} \mathrm{m} \mathrm{m}^{-2} \mathrm{~s}^{-1}\right)$, yet were classified as phototrophic sponges $(\mathrm{P}: \mathrm{R}>1.5)$ at higher irradiances (>500 $\mu \mathrm{mol} \mathrm{m}{ }^{-2} \mathrm{~s}^{-1}$; Fig. 2).

The growth rates of Aplysina fulva and Neopetrosia subtriangularis differed in response to reduced symbiont abundance. In A. fulva, shaded sponges hosted a reduced symbiont from free-living cyanobacteria. Recovered 16S rRNA gene sequences were highly conserved, exhibiting less than $1 \%$ sequence divergence among recovered clones (Table 3) and no significant effect on the topology of phylogenies constructed using ITS sequence data (partition homogeneity test, $\mathrm{p}=1.00$ ).

Symbiont ITS sequences exhibited greater than 5 times the variability of $16 \mathrm{~S}$ sequences (Table 3 ) and revealed 3 distinct symbiont clades within the spongespecific Synechococcus lineage (labeled A, B and C) that were well supported by all phylogenetic analyses (Fig. 4). Deeper nodes representing relationships among the symbiont clades were not well resolved.
Table 2. Aplysina fulva and Neopetrosia subtriangularis. ANOVA of gross production to respiration (P:R) ratios following $6 \mathrm{wk}$ of shaded and control conditions

\begin{tabular}{|lrrrrr|}
\hline Source & Sum of squares & df & Mean square & F-ratio & p \\
\hline A. fulva & & & & & \\
Individual & 7.368 & 3 & 2.456 & 7.832 & 0.001 \\
Irradiance & 25.474 & 3 & 8.491 & 27.078 & $<0.001$ \\
Treatment & 1.031 & 1 & 1.031 & 3.288 & 0.084 \\
Irradiance $\times$ Treatment & 0.780 & 3 & 0.260 & 0.829 & 0.493 \\
Error & 6.585 & 21 & 0.314 & & \\
N. subtriangularis & & & & & \\
Individual & 1.577 & 3 & 0.526 & 4.020 & 0.028 \\
Irradiance & 7.376 & 2 & 3.688 & 28.200 & $<0.001$ \\
Treatment & 0.589 & 1 & 0.589 & 4.505 & 0.051 \\
Irradiance $\times$ Treatment & 0.227 & 2 & 0.114 & 0.868 & 0.440 \\
Error & 1.962 & 15 & 0.131 & & \\
& & & & & \\
\hline
\end{tabular}


The maximum parsimony analysis revealed a polytomy among the 3 symbiont lineages (Fig. 4), while Clade B and Clade C formed a weakly supported $(58 \%)$ monophyletic clade in the maximum likelihood

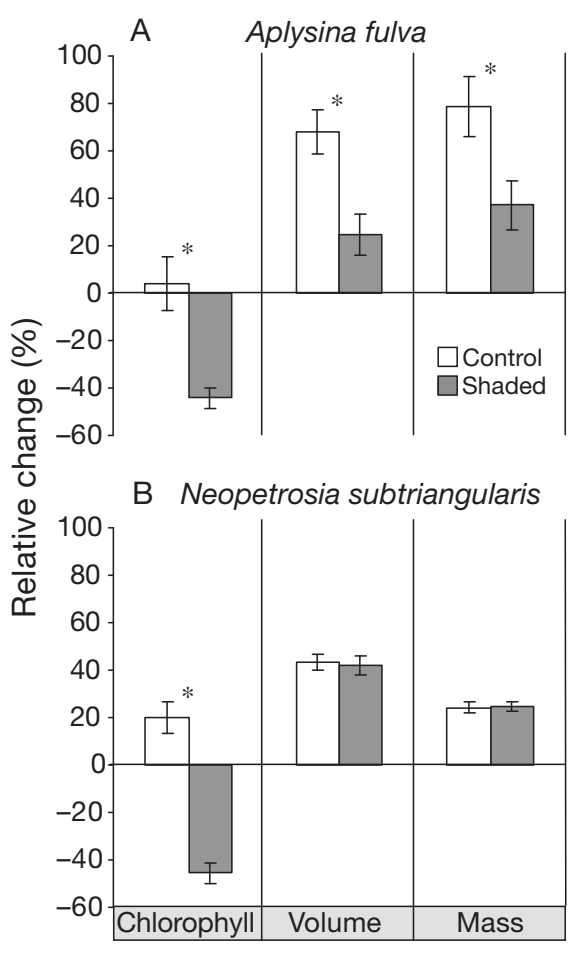

Fig. 3. (A) Aplysina fulva ( $\mathrm{n}=5$ ) and (B) Neopetrosia subtriangularis $(\mathrm{n}=9)$. Effects of shading on relative change in chl a concentrations (symbiont load), holobiont volume, and mass (mean $\pm 1 \mathrm{SE}$ ). ${ }^{*} \mathrm{p}<0.05$ for the difference between control and shaded treatments phylogeny and a modestly supported clade $(0.81)$ in the Bayesian phylogeny. In contrast, Clades A and B formed a weakly supported (55\%) monophyletic clade in the NJ phylogeny.

Cyanobacterial ITS sequences also revealed finescale differences in the symbiont communities of the 2 host sponge species. The symbiont community in Aplysina fulva was dominated by Clade A cyanobacteria, accounting for $83.3 \%$ of recovered symbionts and isolated from all host individuals. Clade B cyanobacteria were identified in 2 A. fulva samples and represented $16.7 \%$ of the recovered symbiont community, while Clade $\mathrm{C}$ symbionts were absent from A. fulva. In contrast, the symbiont community in Neopetrosia subtriangularis was dominated by Clade B cyanobacteria, accounting for $85.0 \%$ of the recovered symbionts and isolated from all host individuals. Clade $\mathrm{C}$ symbionts were present in one $N$. subtriangularis sample and represented $15.0 \%$ of the recovered symbiont community, while Clade A symbionts were absent from N. subtriangularis.

\section{DISCUSSION}

Field-based shading experiments and molecular phylogenetic analyses revealed that the common coral reef sponges Aplysina fulva and Neopetrosia subtriangularis harbor unique clades of cyanobacterial symbionts that may confer variable nutritional benefits to their hosts. Although shading effectively reduced chl a concentrations in both sponge-cyanobacteria symbioses, this reduction in symbiont load only influenced host sponge growth in A. fulva. These results suggest

Table 3. Neopetrosia subtriangularis (N.s.) and Aplysina fulva (A.f.). Pairwise distance matrix for 16S and ITS rDNA sequences recovered from cyanobacterial symbionts. Left of the diagonal indicates percentage pairwise sequence divergence for 16S gene sequences; right of the diagonal indicates pairwise sequence divergence for ITS gene sequences

\begin{tabular}{|c|c|c|c|c|c|c|c|c|c|c|c|c|c|c|}
\hline $\begin{array}{l}\text { Symbiont } \\
\text { clade }\end{array}$ & $\begin{array}{l}\text { Host sponge } \\
\text { species }\end{array}$ & $\begin{array}{l}\text { N.s. } \\
\text { (PSX } \\
\text { F22) }\end{array}$ & $\begin{array}{c}\text { N.s. } \\
\text { (PSX } \\
\text { F23A) }\end{array}$ & $\begin{array}{l}\text { N.s. } \\
\text { (PSX } \\
\text { F24) }\end{array}$ & $\begin{array}{l}\text { N.s. } \\
\text { (PSX } \\
\text { F25) }\end{array}$ & $\begin{array}{l}\text { N.s. } \\
\text { (PSX } \\
\text { F26) }\end{array}$ & $\begin{array}{l}\text { A.f. } \\
\text { (PSX } \\
\text { F5B) }\end{array}$ & $\begin{array}{c}\text { A.f. } \\
\text { (PSX } \\
\text { F10B) }\end{array}$ & $\begin{array}{c}\text { N.s. } \\
\text { (PSX } \\
\text { F23B) }\end{array}$ & $\begin{array}{c}\text { A.f. } \\
\text { (PSX } \\
\text { F6) }\end{array}$ & $\begin{array}{c}\text { A.f. } \\
\text { (PSX } \\
\text { F7) }\end{array}$ & $\begin{array}{c}\text { A.f. } \\
\text { (PSX } \\
\text { F9) }\end{array}$ & $\begin{array}{l}\text { A.f. } \\
\text { (PSX } \\
\text { F5A) }\end{array}$ & $\begin{array}{c}\text { A.f. } \\
\text { (PSX } \\
\text { F10A) }\end{array}$ \\
\hline B & N.s. (PSXF22) & - & 0.00 & 0.00 & 0.00 & 0.00 & 1.43 & 0.123 & 7.36 & 6.13 & 6.13 & 6.34 & 6.54 & 6.54 \\
\hline B & N.s. (PSXF23A) & 0.00 & - & 0.00 & 0.00 & 0.00 & 1.43 & 0.123 & 7.36 & 6.13 & 6.13 & 6.34 & 6.54 & 6.54 \\
\hline B & N.s. (PSXF24) & 0.00 & 0.00 & - & 0.00 & 0.00 & 1.43 & 0.123 & 7.36 & 6.13 & 6.13 & 6.34 & 6.54 & 6.54 \\
\hline B & N.s. (PSXF25) & 0.00 & 0.00 & 0.00 & - & 0.00 & 1.43 & 0.123 & 7.36 & 6.13 & 6.13 & 6.34 & 6.54 & 6.54 \\
\hline B & N.s. (PSXF26) & 0.00 & 0.00 & 0.00 & 0.00 & - & 1.43 & 0.123 & 7.36 & 6.13 & 6.13 & 6.34 & 6.54 & 6.54 \\
\hline B & A.f. (PSXF5B) & 0.00 & 0.00 & 0.00 & 0.00 & 0.00 & - & 1.43 & 6.34 & 5.32 & 5.32 & 5.52 & 5.73 & 5.73 \\
\hline B & A.f. (PSXF10B) & 0.14 & 0.14 & 0.14 & 0.14 & 0.14 & 0.14 & - & 7.57 & 5.93 & 5.93 & 6.13 & 6.34 & 6.34 \\
\hline $\mathrm{C}$ & N.s. (PSXF22) & 0.27 & 0.27 & 0.27 & 0.27 & 0.27 & 0.27 & 0.41 & - & 5.52 & 5.52 & 5.73 & 5.93 & 5.93 \\
\hline A & A.f. (PSXF6) & 0.68 & 0.68 & 0.68 & 0.68 & 0.68 & 0.68 & 0.82 & 0.95 & - & 0.00 & 0.20 & 0.41 & 0.41 \\
\hline $\mathrm{A}$ & A.f. (PSXF7) & 0.68 & 0.68 & 0.68 & 0.68 & 0.68 & 0.68 & 0.82 & 0.95 & 0.00 & - & 0.20 & 0.41 & 0.41 \\
\hline A & A.f. (PSXF9) & 0.55 & 0.55 & 0.55 & 0.55 & 0.55 & 0.55 & 0.68 & 0.82 & 0.14 & 0.14 & - & 0.20 & 0.20 \\
\hline A & A.f. (PSXF5A) & 0.68 & 0.68 & 0.68 & 0.68 & 0.68 & 0.68 & 0.82 & 0.95 & 0.00 & 0.00 & 0.14 & - & 0.00 \\
\hline A & A.f. (PSXF10A) & 0.68 & 0.68 & 0.68 & 0.68 & 0.68 & 0.68 & 0.82 & 0.95 & 0.00 & 0.00 & 0.14 & 0.00 & - \\
\hline
\end{tabular}




\begin{tabular}{|ccccc|}
\hline \multicolumn{5}{|c|}{ Support values } \\
Node & MP & ML & NJ & PP \\
\hline 1 & 100 & 100 & 100 & 1.00 \\
2 & 77 & 56 & 98 & 0.56 \\
3 & 100 & 95 & 99 & 1.00 \\
4 & 97 & 89 & 95 & 1.00 \\
5 & 100 & 98 & 100 & 1.00 \\
6 & 99 & 100 & 99 & 1.00 \\
7 & 98 & 90 & 100 & 1.00 \\
\hline
\end{tabular}

2

LPSF7C3

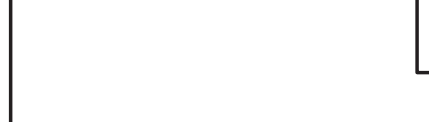

- PSXF23C3

(5) PSXF23C2

\section{Symbiont Clade C}

\section{Symbiont Clade B}

Host: Neopetrosia subtriangularis

Symbiont Clade B

Host: Aplysina fulva

nt Clade C

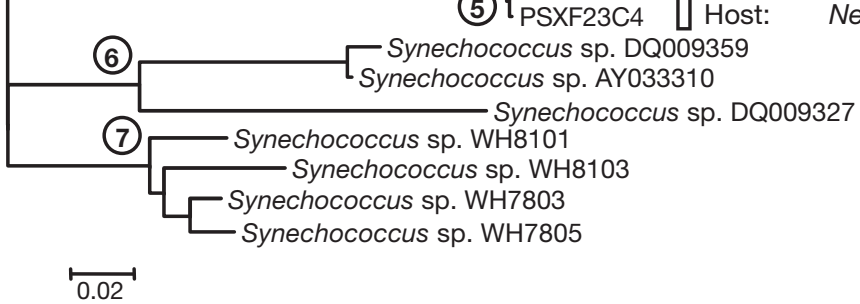

Fig. 4. Phylogeny of complete cyanobacterial 16S-23S rRNA ITS sequences highlighting 3 distinct clades of the symbiotic cyanobacterium 'Candidatus Synechococcus spongiarum' associated with Aplysina fulva and Neopetrosia subtriangularis. Labels on terminal nodes refer to individual symbiont clones. Labels on the right indicate the symbiont clade and host sponge of each cyanobacterial sequence. Outgroup sequences include the top 3 GenBank matches and 4 congeneric cultured strains. Tree topology was obtained from neighbor-joining (NJ) analysis; numbered nodes represent well-supported clades with individual bootstrap percentages from maximum parsimony (MP), maximum likelihood (ML) and NJ analyses and posterior probabilities (PP) from Bayesian phylogenetic analysis located in the upper-left box. Ingroup nodes without numbers have less than $95 \%$ boot strap support from NJ analysis and weaker support from all other analyses. Scale bar: 0.02 nucleotide substitutions per site

that the cyanobacterial symbionts of A. fulva may play a pivotal role in host metabolism and ecology by providing supplemental nutrition that enhances host growth rates. In $N$. subtriangularis, short-term decreases in symbiont load had no effect on host growth, suggesting either that these cyanobacterial symbionts do not affect host metabolism or that this sponge can compensate for the loss of its symbionts. Other symbiont-derived benefits that may increase long-term host fitness (e.g. secondary metabolite production or UV protection) remain to be investigated in both species.
Gross productivity and respiration rates measured for Aplysina fulva and Neopetrosia subtriangularis highlight the effects of light intensity on P:R ratios and the subsequent trophic classification of spongecyanobacteria associations. Both sponge species were classified as heterotrophic ( $\mathrm{P}: \mathrm{R}<1.5)$ at low irradiances $\left(<250 \mu \mathrm{mol} \mathrm{m}{ }^{-2} \mathrm{~s}^{-1}\right)$ and phototrophic $(\mathrm{P}: \mathrm{R}>1.5)$ at high irradiances (>500 $\mu \mathrm{mol} \mathrm{m} \mathrm{m}^{-2} \mathrm{~s}^{-1}$; Fig. 2). Previous P:R measurements by Wilkinson (1987) used irradiances of 200 and $400 \mu \mathrm{mol} \mathrm{m} \mathrm{m}^{-2} \mathrm{~s}^{-1}$ to characterize spongecyanobacteria symbioses from Indo-Pacific and Carib- 
bean coral reefs. These conditions were based on in situ measurements of light intensity at Davies Reef, Great Barrier Reef, at 10 and $20 \mathrm{~m}$ depth. The Caribbean sponges investigated in the present study are commonly found at depths less than $10 \mathrm{~m}$ (Diaz 2005) where seasonal fluctuations in light intensity can range between 500 and $1500 \mu \mathrm{mol} \mathrm{m}{ }^{-2} \mathrm{~s}^{-1}$ (Vermeij \& Bak 2002). These data suggest that $P: R$ measurements obtained at high irradiances are more indicative of natural conditions and in situ photosynthetic activity for A. fulva and N. subtriangularis. Thus, previous studies may have underestimated the photosynthetic activity of Caribbean sponge-cyanobacteria symbioses.

We expected to observe differences in $P: R$ ratios between the control and shaded treatments for both sponge species. Instead, the reduced symbiont load in each species did not impact $\mathrm{P}: \mathrm{R}$ ratios, despite a trend towards significant differences (Table 2). Potential explanations for this result could include a lack of statistical power, since only 4 replicates were tested. Holding these sponges in shaded outdoor aquaria for a week during these measurements may have also impacted either their photosynthetic output or respiration rates. In addition, the cyanobacteria remaining in shaded sponges may have increased their photosynthetic output as their populations decreased, thereby buffering the effect of reduced symbiont load on the $\mathrm{P}: \mathrm{R}$ ratio. Additional experiments are needed to address the mechanisms by which symbiont load affects both cyanobacterial photosynthetic rate and host sponge respiration.

The fine-scale phylogenetic utility of the cyanobacterial 16S-23S rRNA ITS region has promising applications for resolving the host specificity of the spongeassociated lineage of Synechococcus. As demonstrated in the present study, cyanobacterial 16S rRNA gene sequences are often too conserved to resolve fine-scale relationships and may mask important ecological and physiological differences among closely related clades. Previous studies reported that cyanobacterial species exhibiting $>97 \%$ 16S rRNA gene sequence identity can inhabit distinct ecological niches (Moore et al. 1998) and exhibit large differences in whole genome size, gene number and gene identity (Rocap et al. 2003). Although past reports show little host specificity of $S$. spongiarum based on $16 \mathrm{~S}$ rRNA gene sequences (Steindler et al. 2005, Thacker 2005, Taylor et al. 2007a), our results demonstrate that less-conserved molecular markers can reveal host-specific clades, consistent with recent reports of vertical transmission of S. spongiarum (Usher et al. 2005). Additionally, physiological differences among these distinct symbiont clades may affect host-symbiont interactions and account for the variable responses to shading observed in the 2 host sponge species investigated.
Future metagenomic investigations of these symbiont clades may reveal the genetic differences underlying these variable physiological outcomes (Taylor et al. 2007b).

An alternative hypothesis is that both host species receive supplemental nutrition from their symbionts, but vary instead in the plasticity of their nutritional mode. For example, the Mediterranean sponge Petrosia ficiformis activates heterotrophic metabolic pathways in response to the loss of cyanobacterial symbionts (Arillo et al. 1993). Recent reports from coraldinoflagellate symbioses demonstrate that some host corals are able to increase their heterotrophic feeding rates and replenish nutrient stores during bleaching, when symbiont populations are reduced or absent (Grottoli et al. 2006). Similarly, Neopetrosia subtriangularis may have the ability to increase heterotrophic feeding rates when ambient light conditions change and symbiont photosynthetic activity is reduced, yielding similar growth rates of shaded and control individuals. In Aplysina fulva, the symbiosis may be more specialized, with the host sponges dependent on symbiont-derived nutrition and lacking flexibility in their nutritional mode, yielding reduced growth rates in the shaded treatments. Future investigations involving direct observations of filtration rates, filtration efficiency, and heterotrophic versus autotrophic nutrient assimilation will be needed to test this hypothesis.

Our findings suggest that Caribbean spongecyanobacteria associations are characterized by genetically distinct clades of symbionts that may confer variable nutritional benefits to their hosts, with some host species deriving substantial nutrition from symbiont photosynthesis. The evolution of spongecyanobacteria symbioses represents an important adaptation of sponges to the oligotrophic coral reef environment, with symbiont-derived autotrophic nutrition providing resources for increased sponge growth and competitive ability. In contrast to previous reports (Wilkinson 1987), our measurements of the common occurrence (Erwin \& Thacker 2007) and high photosynthetic activity of sponge-cyanobacteria associations suggest that these symbioses make major contributions to primary productivity on Caribbean reefs. Additional studies of sponge-cyanobacteria symbioses will further reveal the diversity of sponge-associated cyanobacteria, the importance of these symbionts to sponge ecology and their impacts on nutrient cycling and other ecosystem functions.

Acknowledgments. We thank R. Collin, C. Diaz, G. Jacome, P. Gondola, A. Castillo, A. Amat and the staff of the Smithsonian Tropical Research Institute's (STRI) Bocas del Toro Research Station for field and laboratory support. Funding was provided by the National Science Foundation under Grant No. 0209329 awarded to R.W.T. and by a grant from the 
National Institute for Undersea Science and Technology awarded to R.W.T. Additional funding was provided by grants from the Society of Integrative and Comparative Biology, the Sigma Xi Research Society and the STRI Short-Term Fellowship Program awarded to P.M.E. M. Salazar and the UAB CFAR Sequencing Core Facility provided DNA sequencing support; this work was facilitated by the infrastructure and resources provided by National Institutes of Health (NIH) CFAR Core Grant P30 AI27767.

\section{LITERATURE CITED}

Arillo A, Bavestrello G, Burlando B, Sarà M (1993) Metabolic integration between symbiotic cyanobacteria and sponges: a possible mechanism. Mar Biol 117:159-162

Birkeland C (1997) Life and death of coral reefs. Chapman \& Hall, New York

Carballo JL, Ávila E (2004) Population dynamics of a mutualistic interaction between the sponge Haliclona caerulea and the red alga Jania adherens. Mar Ecol Prog Ser 279: 93-104

Diaz MC (2005) Common sponges from shallow marine habitats from Bocas del Toro region, Panama. Caribb J Sci 41: 465-475

Erwin PM, Thacker RW (2007) Incidence and identity of photosynthetic symbionts in Caribbean coral reef sponge assemblages. J Mar Biol Assoc UK 87:1683-1692

Flatt PM, Gautschi JT, Thacker RW, Musafija-Girt M, Crews P, Gerwick WH (2005) Identification of the cellular site of polychlorinated peptide biosynthesis in the marine sponge Dysidea (Lamellodysidea) herbacea and symbiotic cyanobacterium Oscillatoria spongeliae by CARD-FISH analysis. Mar Biol 147:761-774

Grottoli AG, Rodrigues LJ, Palardy JE (2006) Heterotrophic plasticity and resilience in bleached corals. Nature 440: 1186-1189

Iteman I, Rippka R, de Marsac NT, Herdman M (2000) Comparison of conserved structural and regulatory domains within divergent 16S rRNA-23S rRNA spacer sequences of cyanobacteria. Microbiology 146:1275-1286

Kumar S, Tamura K, Nei M (2004) MEGA3: integrated software for molecular evolutionary genetics analysis and sequence alignment. Brief Bioinform 5:150-163

Moore LR, Rocap G, Chisholm SW (1998) Physiology and molecular phylogeny of coexisting Prochlorococcus ecotypes. Nature 393:464-467

Muscatine L, Porter W (1977) Reef corals: mutualist symbioses adapted to nutrient-poor environments. Bioscience 27: 454-460

Muscatine L, McCloskey LR, Marian RE (1981) Estimating the daily contribution of carbon from zooxanthellae to coral animal respiration. Limnol Oceanogr 26:601-611

Nübel U, Garcia-Pichel F, Muyzer G (1997) PCR primers to amplify 16S rRNA genes from cyanobacteria. Appl Environ Microbiol 63:3327-3332

Parsons TR, Maita Y, Lalli CM (1984) A manual of chemical and biological methods for seawater analysis. Pergamon Press, New York

Posada D, Crandall KA (1998) MODELTEST: testing the model of DNA substitution. Bioinformatics 14:817-818

Regoli F, Cerrano C, Chierici E, Bompadre S, Bavestrello G (2000) Susceptibility to oxidative stress of the Mediterranean demosponge Petrosia ficiformis: role of endosym-

Editorial responsibility: Charles Birkeland,

Honolulu, Hawaii bionts and solar irradiance. Mar Biol 137:453-461

Rocap G, Distel DL, Waterbury JB, Chisholm SW (2002) Resolution of Prochlorococcus and Synechococcus ecotypes by using 16S-23S ribosomal DNA internal transcribed spacer sequences. Appl Environ Microbiol 68:1180-1191

Rocap G, Larimer FW, Lamerdin J, Malfatti S and others (2003) Genome divergence in two Prochlorococcus ecotypes reflects oceanic niche differentiation. Nature 424: 1042-1047

Ronquist F, Huelsenbeck JP (2003) MrBayes3: Bayesian phylogenetic inference under mixed models. Bioinformatics 19:1572-1574

Rützler K (1990) Associations between Caribbean sponges and photosynthetic organisms. In: Rützler K (ed) New perspectives in sponge biology. Smithsonian Institute Press, Washington, DC, p 455-466

Schönberg CHL, Loh WKW (2005) Molecular identity of the unique symbiotic dinoflagellates found in the bioeroding demosponge Cliona orientalis. Mar Ecol Prog Ser 299: 157-166

Stanley GD Jr (2006) Photosymbiosis and the evolution of modern coral reefs. Science 312:857-858

> Steindler L, Huchon D, Avni A, Ilan M (2005) 16S rRNA phylogeny of sponge-associated cyanobacteria. Appl Environ Microbiol 71:4127-4131

Stewart FJ, Cavanaugh CM (2007) Intragenomic variation and evolution of the internal transcribed spacer of the rRNA operon in bacteria. J Mol Evol 65:44-67

Swofford DL (1998) PAUP*: phylogenetic analysis using parsimony ( ${ }^{*}$ and other methods), Version 4.0b10. Sinauer Associates, Sunderland, MA

> Taylor MW, Radax R, Steger D, Wagner M (2007a) Spongeassociated microorganisms: evolution, ecology, and biotechnological potential. Microbiol Mol Biol Rev 71: 295-347

> Taylor MW, Thacker RW, Hentschel U (2007b) Evolutionary insights from sponges. Science 316:1854-1855

Thacker RW (2005) Impacts of shading on sponge-cyanobacteria symbioses: a comparison between host-specific and generalist associations. Integr Comp Biol 45:369-376

> Thompson JD, Gibson TJ, Plewniak F, Jeanmougin F, Higgins DG (1997) The CLUSTAL_X windows interface: flexible strategies for multiple sequence alignment aided by quality analysis tools. Nucleic Acids Res 25:4876-4882

Usher KM, Sutton DC, Toze S, Kuo J, Fromont J (2004) A new species of cyanobacterial symbiont from the marine sponge Chondrilla nucula. Symbiosis 36:183-192

> Usher KM, Sutton DC, Toze S, Kuo J, Fromont J (2005) Intergenerational transmission of microbial symbionts in the marine sponge Chondrilla australiensis (Demospongiae). Mar Freshw Res 56:125-131

> Usher KM, Kuo J, Fromont J, Toze S, Sutton DC (2006) Comparative morphology of five species of symbiotic and nonsymbiotic coccoid cyanobacteria. Eur J Phycol 41:179-188

- Vermeij MJA, Bak RPM (2002) How are coral populations structured by light? Marine light regimes and the distribution of Madracis. Mar Ecol Prog Ser 233:105-116

Wilkinson CR (1987) Interocean differences in size and nutrition of coral reef sponge populations. Science 236: 1654-1657

> Wilkinson CR, Fay P (1979) Nitrogen fixation in coral reef sponges with symbiotic cyanobacteria. Nature 279: $527-529$

Submitted: September 18, 2007; Accepted: February 27, 2008 Proofs received from author(s): June 18, 2008 